revista ANTHROPOLÓGICAS

Ano 22, 29(1): 1-27, 2018

\title{
Espetacularização e Apropriação Moral: Disputas morais, vergonha e desgraça em um bairro periférico da cidade de João Pessoa - PB
}

Mauro Guilherme Pinheiro Kourya

Raoni Borges Barbosa ${ }^{b}$

\begin{abstract}
Este artigo aborda a disputa moral em torno de um regime de pânico instaurado pela mídia sob o impacto de uma chacina espetacularizada como 'Chacina do Rangel' no cotidiano dos moradores do bairro popular Varjão/Rangel, na cidade de João Pessoa - PB. O Varjão/Rangel foi colocado em evidência pela crueldade e banalidade da chacina, o que mobilizou uma série de processos de apropriacão moral e controle social pelo poder público, mídia e igreja, principalmente a católica. A discussão desenvolvida neste artigo enfatiza a disputa moral acontecida logo após a 'Chacina do Rangel' em torno de um projeto de criação de um santuário em memória das vítimas da chacina no local onde a tragédia aconteceu. $\mathrm{O}$ artigo faz uma etnografia das negociacões, tensões, desentendimentos e impasses em torno da possibilidade da construção do santuário, como forma de controle social de um lugar estigmatizado como violento e perigoso.
\end{abstract}

Varjão/Rangel; Chacina; 'Chacina do Rangel'; Pânico moral; Disputa moral; Santuário.

Este artigo aborda as disputas e apropriações morais em torno da 'Chacina do Rangel'1 em um regime de pânico instaurado pela mídia, na cidade de João Pessoa - PB e no cotidiano dos moradores do bairro

a Professor do Programa de Pós-Graduação em Antropologia (UFPEB) e Coordenador do GREM - UFPB. Email: maurokoury@gmail.com.

b Doutorando em Antropologia pelo Programa de Pós-Graduação em Antropologia (UFPE) e Pesquisador do GREM - UFPB. Email: raoniborgesb@gmail.com. 
do Varjão/Rangel, cenário deste crime. Busca compreender a relação entre medos, vergonha e cotidiano, na cidade e no bairro em questão, a partir do evento ocorrido no dia 09 de julho de 2009. Neste episódio um casal invade a residência de uma família vizinha, com a qual tinha fortes laços de parentesco, compadrio e solidariedade, e a golpe de foice e facão, trucida toda a família por um motivo aparentemente banal: a repreensão de um filho do casal agressor pela mãe da família vitimada e por uma repartição, considerada injusta, de uma galinha.

O caso toma conta da mídia local da cidade de João Pessoa, com grande estardalhaço e espetacularização do episódio. O que causa um sentimento de vergonha, de estigmatização e de medos entre os moradores do bairro e da cidade como um todo, de um lado; e, do outro, sentimentos de revolta e de vingança, ocasionando uma catarse pública ao longo do processo de vivência coletiva da tragédia.

Este artigo busca demonstrar, deste modo, como a articulação de sentimentos específicos em um cenário de tensão, conflitos e disputas morais compõe uma figuração moral e ameaça toda uma cultura emotiva, redefinindo e remontando identidades e relações no sentindo oposto ao que o bairro buscava para si. É neste sentido que o caso da 'Chacina do Rangel' aparece para o Varjão/Rangel como vergonha desgraça ${ }^{2}$, ou seja, como elemento de desfiguração de uma busca coletiva de inclusão social e moral nos códigos da cidade.

O presente estudo, então, procura discutir e compreender como se articulam as emoções vergonha e quebra de confiança coletiva para a montagem de uma justificação da ação mais ampla que é a moral e as emoções enquanto cultura emotiva. Em outras palavras, se discute como os indivíduos vivenciam e estabelecem significados morais às suas ações e a dos outros em um dado momento cultural e social, bem como se problematiza o papel da mídia na elaboração dos contornos que ressignificam esses sentidos em pânico moral.

Parte da hipótese de que o episódio visto através dos sentimentos e padrões de confiança e vergonha permite perceber e compreender a constituição de uma esfera de significados simbólicos além da esfera 
econômica, obedecendo a uma lógica de reparação e justiça distinta. Lógica esta somente inteligível na análise de tempo longo e de amplas cadeias de interpendência (Elias 1994) que revelam em nível micro as acomodações, materiais e simbólicas, indeterminadas entre os atores sociais em jogo.

Objetiva apresentar, no interior de uma perspectiva interacionista da antropologia das emoções e da moralidade, uma reflexão de base etnográfica sobre os processos de solidariedade e conflito entre os moradores do bairro do Varjão/Rangel, na cidade de João Pessoa, Paraíba. Processos estes analisados no âmbito de uma situação limite (Jaspers 1974) generalizada, a 'Chacina do Rangel', de pânico moral (Young 1971; Cohen 2002; Garland 2008; Goode \& Ben-Yehuda 1994) e de vergonha desgraça (Scheff 1990) no bairro, e de disputas morais entre os seus moradores e a cidade de João Pessoa, - entendida aqui também como um discurso moralizador organizado a partir principalmente da mídia local como empreendedor moral (Becker 2008 e 2009).

Trata-se, assim, de um estudo sobre a expansão da cidade nas últimas décadas e as tensões resultantes deste processo de formação do urbano contemporâneo brasileiro na destruição de antigas comunidades, com seus tempos e espaços próprios e sua acelerada conformação como espaço periférico, de desordem e estigma. Isto é, a situação atual que configura o cenário da 'Chacina do Rangel' e a partir do qual são acionados discursos de desculpa e acusação (Werneck 2009 e 2011) de si, do próximo e do distante.

Nas disputas morais que mobilizaram as identidades e os moradores da cidade e do bairro está em jogo a reputação dos lugares urbanos como espaços interacionais que reconhecem os códigos da modernidade. Códigos estes que se configuram como ideais de racionalidade, progresso, higiene, impessoalidade e ordem.

Neste embate em torno das significações e implicações da chacina, se acusam e se ressentem mutuamente bairro e cidade. É neste jogo complexo de conformação de códigos de moralidade que a banalidade $^{3}$ deste crime instrumentalizado como argumento moral assume 
significados específicos que constrangem e envergonham a cidade de João Pessoa, desqualificando a sua reputação como espaço civilizado. E ressente o morador do bairro através do discurso generalizado e acusatório da mídia local e da cidade, que imputa a tragédia aos atributos morais daquela sociabilidade.

O envergonhamento da cidade em relação ao bairro, potencializado pela espetacularização da chacina pela mídia, que a denominou como 'Chacina do Rangel', por sua vez pesou moralmente sobre o morador do Varjão/Rangel. Morador este que se esforça cotidianamente em diferenciar espaços simbólicos moralmente marcados no imaginário local: o Varjão e o Rangel como lugares distintos e de lógicas actanciais próprias.

O artigo está organizado em três partes. A primeira apresenta uma breve história do bairro do Varjão/Rangel no interior da lógica de expansão e modernização da cidade de João Pessoa. A segunda parte trata mais especificamente da dinâmica interna da 'Chacina do Rangel', apresentando o cenário com seus atores, assim como as disputas morais em torno da mesma. A terceira parte, por fim, contextualiza a transformação da tragédia em espetáculo e argumento moral pela mídia local através de um projeto de apropriação moral do ocorrido no sentido de sua instrumentalização para a pacificação do bairro e de construção de uma capela em homenagem às vítimas da tragédia. Projeto este em que embarcaram também os moradores do bairro, a igreja católica e o poder público municipal e estadual.

\section{O Varjão/Rangel no processo de expansão e modernização da cidade}

O bairro do Varjão/Rangel, que nasceu Varjão, teve a sua ocupação iniciada de forma progressiva a partir dos anos setenta do século passado às margens do Rio Jaguaribe e fazendo fronteira com a reserva florestal de mata Atlântica conhecida como Mata do Buraquinho, muito embora se tenha registros de moradores vivendo em várias pequenas comunidades na grande várzea do Rio Jaguaribe a partir da 
década de 1920. O Varjão/Rangel é atualmente um bairro popular da zona oeste da cidade de João Pessoa, próximo ao centro velho da capital paraibana e fazendo fronteiras com outros bairros populares também considerados violentos nas estatísticas policiais e no imaginário da cidade, com notícias recorrentes na mídia sobre prisões, mortes e assaltos no bairro e fora dele por seus moradores ${ }^{4}$.

O bairro é oficialmente nominado de Varjão, mas que se configura desde o final dos anos de 1970 no imaginário do morador como Rangel. Essa dualidade de nomes reflete uma disputa moral inconclusa e emocionalmente desgastante para o morador entre um bairro imaginado que se pretende civilizado (Rangel) e outro enquadrado como marginal (Varjão).

O bairro é caracterizado ainda hoje pela sua formação a partir de redes homofílicas pautadas no parentesco, na vizinhança e no compadrio, desde a sua mais remota origem. O que o conforma como um lugar de intensa pessoalidade, potencializada pela co-presença quase que ininterrupta de seus moradores nos espaços de sociabilidade cotidianos, onde todos se misturam, para o observador externo, e os códigos de comportamento público e privado pouco se diferenciam ${ }^{5}$.

O morador do Varjão/Rangel aciona, assim, um discurso de desculpas e acusações de si e do outro, definindo as situações sociais a partir de enquadres interpretativos que orientam as ações dentro de um cenário de ambiguidades. Ambiguidades estas que se apresentam na tensão entre os laços de solidariedade e de pertença ao bairro, e nos conflitos e na negação do outro identificado como elemento de desordem moral que a cidade imputa ao bairro e cobre de vergonha o próprio morador.

É nesta dinâmica coletiva de desculpa, acusação e disputa moral que o bairro aparece como cultura emotiva fragmentada, ambígua e ambivalente, e com grande sofrimento social por parte dos moradores que, ao mesmo tempo em que eles se solidarizam também se estranham como iguais e diferentes em um mesmo movimento de classificação e hierarquização moral. Isso se reflete na dualidade de 
nomes que representam lugares excludentes, mas sobrepostos e que se referenciam em contextos e situações cotidianos protagonizados pelos moradores do bairro.

Desta forma o morador articula e utiliza lugares como atributos morais classificatórios a partir de um lugar de fala que diferencia o outro relacional como morador do Varjão (marginal) ou do Rangel (civilizado) em um sistema tensional de classificações gerador de fofocas, dissensos, intrigas, medos, mágoas e ressentimentos. Esta cultura emotiva se caracteriza, assim, pela possibilidade sempre latente de fragmentação dos laços de solidariedade, combinando o morador um discurso agressivo de amor e ódio pelo bairro e pelos outros relacionais.

\section{A dinâmica interna da 'Chacina do Rangel'}

O bairro do Varjão/Rangel tem sido alvo de um interesse acentuado da cidade, entendida como argumento de conformação moral por parte da administração pública, da mídia e da própria opinião do homem comum, desde que foi palco de um crime entre iguais conhecido como a 'Chacina do Rangel', em 2009 (Koury et al. 2013). Esta tragédia desencadeou uma dinâmica de envergonhamento de toda a cidade de João Pessoa, e do estado da Paraíba, bem como reforçou o estigma contra o bairro e seus moradores na medida em que desconstruiu o esforço de dissociar a nominação 'Rangel' do contexto 'Varjão' de sociabilidade de baixo padrão moral (Barbosa 2016). Nas palavras de uma moradora local, a tragédia "chocou a vizinhança toda, geral. E finalmente esse negócio abalou o mundo geral. Aqui foi uma banda do céu que caiu" ${ }^{\text {. }}$

A fala desta moradora, ao afirmar enfaticamente o sentimento de vergonha desgraça (Scheff 1990) e de humilhação como forma de julgamento moral do morador do bairro em face da tragédia, situa este momento de ruptura na sociabilidade do bairro em relação a um passado em que as nominações Varjão e Rangel eram minimamente 
dissociadas no imaginário do morador. O Varjão/Rangel passou, com essa tragédia, a ser encarado como lugar a ser pacificado principalmente pelas forças policiais e pela reconfiguração simbólica do crime ali ocorrido.

O casal de criminosos era ligado à família chacinada por fortes laços de parentesco e compadrio. Este laço, não somente de sangue, mas, sobretudo, de gratidão (Simmel 2010) e de fidelidade (Simmel 2003), vem a ser o elemento desfeito em um processo longo, milimétrico e muitas vezes inconsciente na micropolítica cotidiana das emoções (Rezende \& Coelho 2010). Este processo intersubjetivo de construção de sentidos sociais se reforça no acúmulo de pequenas mágoas e desentendimentos que redundam em ressentimentos profundos entre os relacionais, quebra de confiança e tem, como desenlace, a violência entre iguais que caracteriza a destruição de vínculos de intensa proximidade e pessoalidade, em que o Eu e o Outro se constroem enquanto extensão um do outro, como projeto coletivo e moralidade específica.

Esta socialidade primária (Park et al. 1925; Berger 2001), com suas hierarquias invisíveis, estaria baseada em uma forte solidariedade e reciprocidade nas ações comuns em ambas as famílias vizinhas. $\mathrm{O}$ início da história das duas famílias é comum a várias outras no processo de migração campo-cidade no Brasil.

Um tempo atrás a família agora vitimada migrou para a cidade de João Pessoa, saindo de uma história de miséria no interior da Paraíba. Ao chegar à capital, estabeleceu-se no bairro do Varjão/Rangel e lá, ocupando um terreno baldio, construiu a sua moradia. Sem encontrar emprego, o casal começa a coletar lixo para vender e se alimentar. Alguns anos depois, um primo do marido do casal segue os passos dele e, se inserindo na rede de migração comum nos processos migratórios de grupos populares no Brasil, muda para João Pessoa e se estabelece também no Varjão/Rangel, na casa dos primos, que o acolhem, construindo a seguir uma moradia no mesmo terreno ocupado pelo primeiro casal. 
A partir desse acolhimento familiar, o primeiro casal inicia o segundo no processo de adaptação à cidade. A dificuldade de emprego formal não diminui a atratividade do espaço urbano, onde se percebe uma maior facilidade de sobrevivência em relação ao município do sertão rural de onde vieram. As duas famílias participam, assim, dessa nova inserção à cidade e a luta pela sobrevivência diária é minorada pela solidariedade e reciprocidade nas trocas materiais e simbólicas de cada um, após um dia de trabalho. Nesse ritmo cotidiano as duas famílias iam sobrevivendo, com laços cada vez mais estreitos, não só os de consanguinidade, mas também os laços de confiança e solidariedade estabelecidos entre eles, e o da gratidão e lealdade geradas pelas formas de inserção de uma família pela outra na urbe, bem como nos processos harmônicos da partilha dos bens achados e dos cuidados com os filhos de ambos os casais.

Simmel ${ }^{7}$ entende os processos de gratidão e de fidelidade, sem os quais não se estabelece a reciprocidade mínima para o estranhamento positivo entre culturas subjetivas, como fundamentais para a construção da confiança. A gratidão aponta para o exercício de memória social, alimentado continuamente nas trocas materiais e simbólicas de, entre outros, pequenos favores, que funda o reconhecimento de si no e outro e vice-versa.

Para Koury (2000, 2002, 2003, 2005, 2005a, 2008, 2009, 2010, 2010a, 2011, 2012), a confiança promove a segurança íntima de procedimento, de compartilhamento das regras do jogo interacional: o outro é classificado, cognitiva, emocional e moralmente como prolongamento do Eu, de modo que se torna sujeito de fala e de ação, um sujeito de sentidos. A confiança, emoção basilar no processo de conformação de um indivíduo moral, aponta para elementos de solidariedade dos que fazem parte do grupo, - ainda que este se limite a cadeias familísticas de interdependência, - bem como para marcadores mais objetivos, tais como comportamentos sociais singulares, específicos que operam como fronteiras Nós-Eles. 
A construção da confiança possibilita, ainda, o nascimento simbólico para o mundo através das trocas intersubjetivas, de modo que um lugar de visibilidade se organiza como o lugar de semelhança e de identificação, de familiaridade e de afetos, mas, também, de possibilidade de diferenciação, individuação e de fundação de individualidades. O processo de construção da confiabilidade, em contrapartida, desencadeia uma ação de conceber confiança ao outro relacional.

A confiança e a confiabilidade comunicam um sentimento de proteção e de lealdade a uma comunidade moral, a partir da qual o indivíduo moral infere os fins (valores) e os meios (normas) da ação social legítima. O confiar e o conceber confiança, assim, são operadores da ação social no sentido em que minimizam o problema da contingência e da complexidade inerentes ao espaço interacional, sempre tenso, conflitual, indeterminado e em constante refazer-se.

A confiança e a confiabilidade são os elementos basilares do elo de reciprocidade, sobre o qual o sistema moral se organiza através de processos intersubjetivos e comunica, na dinâmica deste mesmo sistema moral, sentimentos de honra, honestidade, sinceridade, pureza de sentimentos e outros, bem como define o que pode vir a ser classificado como ofensa moral (Berger 2015). Fenômeno este que se organiza enquanto retórica e performatização bastante singular, muitas vezes não percebida por observadores externos (Cardoso de Oliveira 2011).

No caso da 'Chacina do Rangel', a irrupção de violência, naquela madrugada de 09 de Julho de 2009, ficou para o imaginário da população da cidade de João Pessoa, em linhas gerais, como sendo motivada tão somente pela repartição injusta e mesquinha de uma galinha pelas famílias envolvidas na tragédia. O crime, torpe em seus motivos, foi assim considerado e pesado pela justiça local, enquanto que a população em choque buscava explicações de caráter psicologizante, biologizante e também místico-religiosas para entender a mente dos assassinos, sintetizada e instrumentalizada pela mídia local como o 'Monstro do Rangel'.

Ocorre, porém, que a dissolução dos laços de gratidão, fidelidade e reciprocidade entre as famílias que viviam praticamente juntas, foi 
também classificada moralmente, pela cidade e pelo próprio morador do bairro, como uma quebra de confiança profunda e de transgressão da moralidade que humaniza o ator social. A associação ao bairro positivamente imaginado, Rangel, de uma condição não humana, ainda por moralizar, enquanto elemento também explicativo do crime que sujava, contagiava e poluía toda a cidade e mesmo o estado da Paraíba, impactou fortemente na cultura emotiva do Varjão/Rangel.

Como colocou Dona Neuza, vizinha próxima, ali se estabelecera em razão da destruição da reputação já problemática do lugar uma situação de liminaridade (Turner 1974), de silêncio e de interdito, que exigia uma reparação compensatória, mas também uma reordenação moral condizente. Tão logo a população do bairro e das comunidades adjacentes soube da tragédia, personalizada pela mídia local como ato perverso do 'Monstro do Rangel', uma multidão se dirigiu para o local do evento e o destruiu em um espetáculo de fúria catártica.

Cabe frisar, ainda, que os envolvidos no crime, o casal Carlos José dos Santos, e Edileuza Oliveira dos Santos, foi por pouco salvo pelos policiais que chegaram à Rua Oswaldo Lemos no momento de salvá -los do linchamento popular incitado pelas rádios locais. O malogro do linchamento físico intensificou o linchamento moral do casal por parte da população do bairro e da cidade, que se estendeu por mais de um ano desde o acontecido.

Seguiu-se a esse ímpeto de justiçamento popular, entendido enquanto esforço de linchamento moral dos envolvidos na 'Chacina do Rangel', um conjunto de ações no sentido de organizar no local do crime um espaço de religiosidade popular, ao passo que um processo de vitimização da família assassinada era construído em paralelo com um processo de desfiguração e desumanização do homicida Carlos André, classificado como 'Monstro do Rangel'.

A notícia abaixo ilustra bem como se encontravam os ânimos dos moradores do bairro, então. Bairro este identificado como Rangel, mas associado ao que o morador classifica e hierarquiza moralmente como pertencendo ao lugar do Varjão. 
"A população do Rangel demoliu em regime de mutirão na manhã deste sábado, o local do crime que chocou toda Paraíba na semana passada, onde 7 pessoas de uma mesma família foram vítimas da fúria de selvageria de Carlos André e sua esposa Edileuza. Mesmo com ordem judicial proibindo a demolição do cenário do crime, onde seria periciada e feita a reconstituição, a dezenas de anônimos de toda João Pessoa se fizeram presentes hoje naquele local. Marretas, martelos, pedaços de madeira foram às ferramentas utilizadas para demolir o local do crime que ficou conhecido como a Chacina do Rangel"s.

A ação violenta de um casal em relação ao outro foi movida pelo sentimento de vergonha, na sua forma de raiva ou ira, motivada pela certeza da traição e pelo sentimento de humilhação ali gerado. A compreensão de que uma das partes agiu de má fé em relação à outra parte, suscitando não a desconfiança, mas a quebra de confiabilidade e os laços de reciprocidade que as uniam enquanto projeto comum movimenta o ato violento da chacina.

O desentendimento entre as famílias se inicia quando uma das crianças se queixa aos pais de ter sido posto de castigo pela senhora da outra família. Além disso, o cenário se torna ainda mais tenso em razão da repartição, considerada injusta pelo casal agressor, de uma galinha. Ao achar que a outra família queria passar a perna neles, seja pela atitude da mulher da primeira família que estava cuidando dos filhos dos dois casais enquanto os demais adultos trabalhavam, seja pela repartição considerada injusta do apurado do dia (a galinha), a família agressora provocou uma discussão longa e emocionalmente desgastante.

Depois dessa confrontação moral, sentida como humilhação profunda, quebra de confiança e de confiabilidade, o casal agressor se retira para a casa. Ali continua a rememorar o ato de humilhação, enquanto consomem bebida alcoólica. O casal parte, já durante a madrugada, e bastante transtornado pelo álcool, pelo ressentimento e pelo desgaste físico, emocional e moral, para tomar satisfação e exigir reparação com a outra família.

Loucos de raiva e armados com facão e foice Carlos José Soares e Edileuza Oliveira trucidam a família que os acolheu, e que, naquele 
momento, era classificada como alguém que os tinha lesado: Moisés Soares Filho; Divanise Lima dos Santos, grávida de gêmeos; três filhos mortos; dois filhos que sobrevivem (Figura 1). De acordo com notícias de última hora de um jornal on-line:

"O cenário do crime revela a verdadeira carnificina. Crianças degoladas e partes dos corpos separados por golpes de facão em vários locais da residência. Uma mão de uma das crianças foi encontrada em cima de um guarda roupa da residência" $"$.

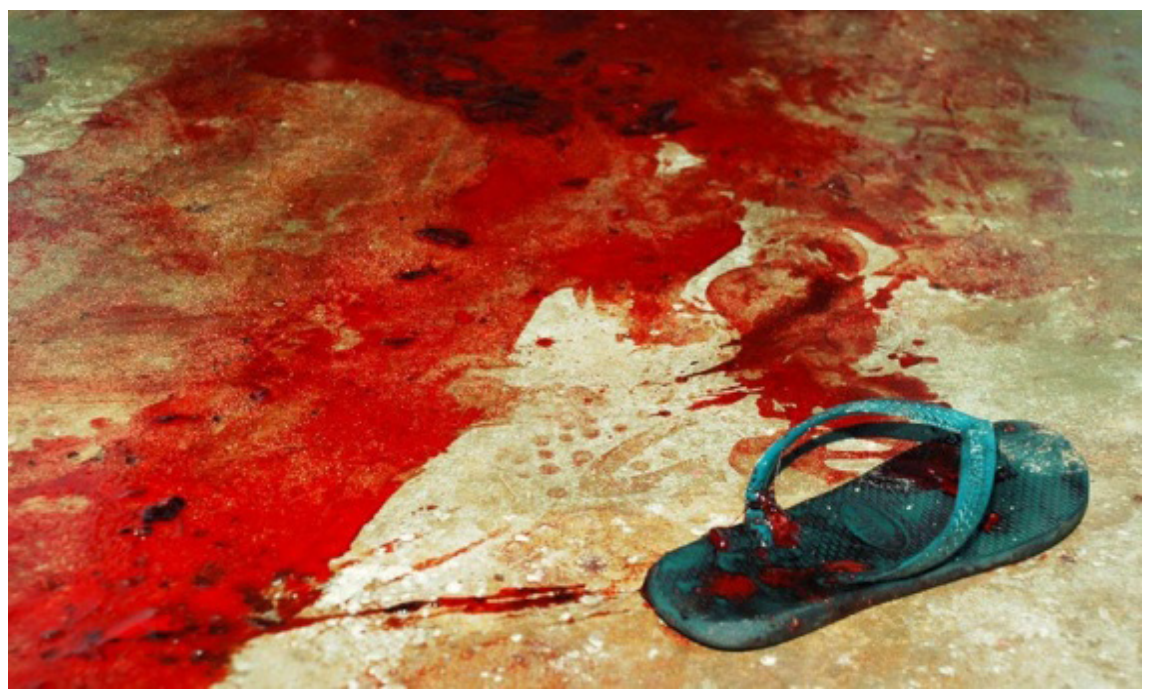

Figura 1: 'Chacina do Rangel' Foto: Felipe Gesteira. Fonte: www.portaldazonasul. com/2014/07/chacina-do-rangel-completa-5-anos-hoje.html.

Após a chacina houve a prisão imediata do casal que, ainda acometidos pelo ato de vingança motivada pela traição do casal com que partilhavam laços de confiança e lealdade, dizem não ter arrependimento do ato. $\mathrm{O}$ fato logo chega à imprensa que brada a desumanidade de tamanha violência pela repartição injusta de uma galinha e pela repreensão também injusta de um dos seus filhos pela mãe da família trucidada, e emociona toda a cidade e todo o bairro onde aconteceu a chacina. 
No velório da família, realizado em uma escola municipal, milhares de pessoas foram velar os corpos e chorar e gritar vingança (Figuras 2, 3 e 4). De acordo com o blog O Be-a-Bá do Sertão $0^{10}$, o então governador do estado da Paraíba, José Targino Maranhão,

"acompanhou, na tarde desta sexta-feira (10 de julho de 2009), o sepultamento dos corpos de Moisés Soares dos Santos, Evanize Soares dos Santos e de seus três filhos, todas vítimas de um crime brutal ocorrido na manhã da quinta-feira (09 de julho de 2009), e que chocou os moradores do bairro do Rangel, na Capital. Antes de comparecer ao velório, ele determinou ao Corpo de Bombeiros que disponibilizasse uma viatura para transportar os corpos durante o enterro, além do apoio da Polícia Militar”.

Ainda segundo o blog acima referenciado,

"cortejo fúnebre foi marcado por clima de forte comoção e, na ocasião, o governador hipotecou solidariedade aos familiares... O sepultamento aconteceu no cemitério do bairro do Cristo Redentor, em meio a muita emoção e revolta da multidão presente".
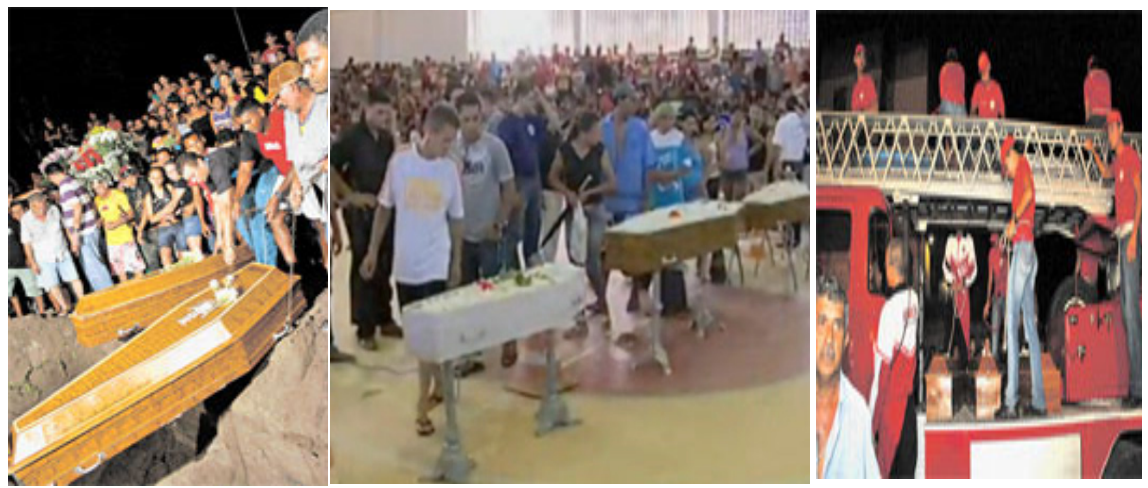

Figuras: 2, 3 e 4 - Uma multidão compareceu ao velório e testemunhou, consternada, o sepultamento dos corpos das vítimas. Os caixões foram transportados ao cemitério por um carro do Corpo de Bombeiros. Fotos: Ovídio Carvalho/

ON/D.A Press Fotos: Ovídio Carvalho/ON/D.A Press. 
Neste clima de comoção e revolta na cidade de João Pessoa, e em que o bairro ainda está acometido por um sentimento de vergonha desgraça, a polícia local também se aproveita da situação para criar uma média nessa comoção social e tortura o acusado. A tortura do autor masculino da chacina, divulgado pela imprensa, causou indignação de um lado da sociedade local e nacional, e, do outro, satisfação pelo sofrimento do 'Monstro do Rangel'. As cenas do vídeo em que Carlos José dos Santos, o 'Monstro do Rangel' ou 'Mata Sete', aparece sendo torturado por funcionários não identificados, que o tratam por 'Cachorro'.

Nos comentários do vídeo populares aprovam a ação de tortura, sugerindo, entre outras coisas, um tiro na cabeça do torturado e o uso de óleo fervendo, choques elétricos e alicates como instrumentos para a maximização da dor e do sofrimento. Ao lado de comentários que desacreditam os Direitos Humanos, Carlos José dos Santos é tratado como 'safado', 'verme', 'vagabundo', 'porco' e 'palhaço'11.

Dias depois, as duas casas onde moravam as famílias vizinhas e aparentadas foram derrubadas por moradores da vizinhança. A casa do assassino, Carlos José, que está no presídio do Roger, também foi destruída (Figura 5). Mas logo depois do crime e como forma de protesto, segundo notícia do PB agora de 18 de julho de $2009^{12}$.

A casa do casal agressor, tida como espaço tomado pelo mal ('moradia do demônio'), teve sua demolição poucas horas depois do casal ser preso, no mesmo dia da chacina. A casa não foi apenas demolida pelos moradores do bairro, mas também teve seus bens saqueados. Estes atos simbólicos foram noticiados pela imprensa como evidências e demonstrações do nojo e da repulsa da população local em relação aos criminosos.

A casa da família vitimada, por seu turno, foi primeiramente lavada, piso e paredes, e teve seus móveis manchados de sangue retirados para a purificação pelo fogo, conforme a notícia publicada no jornal O Norte, de 13 de julho de 2009. No dia 18 de julho a população demoliu a casa em um ritual de orações e de promessa de construção de uma capela naquele lugar. 
Segundo notícia da WSCOM, de 09 de julho de $2010^{13}$ :

"A demolição da casa começou logo na manhã do dia 18 de julho, com clima misto de revolta e comoção. Entre uma marretada e outra, orações eram feitas pelos populares e parentes dos mortos. Amigos das vitimas estiveram presentes e choraram bastante ao lembrar a tragédia, então muito recente. A idéia era que o local se tornasse um local de orações em favor das vitimas de uma das tragédias que mais chocaram a Paraíba"14.

\section{A transformação da tragédia em argumento moral}

A dinâmica de desfiguração (Goffman 1988 e 2012) dos assassinos, ora exercida como busca de vingança, ora como exercício de pacificação e de moralização do espaço urbano ocupado pelo bairro na cidade, destacou o papel da mídia como empreendedor moral (Becker 2008 e 2009). A figura do empreendedor moral aparece no espaço de interações como um catalisador de ações voltadas para a imposição de um projeto coletivo a partir de uma leitura e definição de uma situação dada.

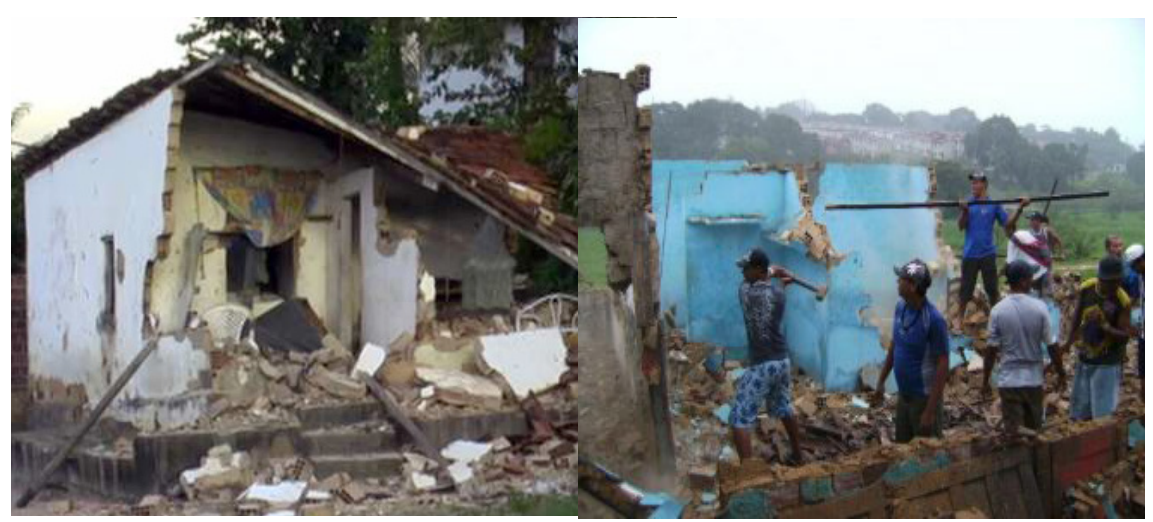

Figuras: 5 e 6 - Casa dos agressores semidemolida pela população do bairro (Fig.5). A casa das vítimas foi demolida pelos próprios vizinhos (Fig.6), para construir uma capela. (Créditos: Walter Paparazzo). 
A análise aqui feita do papel da mídia em relação à chacina remete à noção de Becker (1976) relativa a uma cruzada moral, visando a viabilizar estratégias empreendidas no sentido de eliminação da barbárie advinda de uma sociabilidade violenta e moralmente degradada. No contexto da tragédia, a mídia significou e aglutinou uma série de fatos como 'Chacina do Rangel', construindo para este cenário o personagem do 'Monstro do Rangel'.

Ao considerar as estratégias assumidas pela Prefeitura da cidade de João Pessoa e pelo Governo do Estado da Paraíba em relação à chacina, se pode apreender a grande articulação entre agentes governamentais e a mídia, que rotularam a tragédia e o próprio bairro onde esta aconteceu de 'bárbara', 'perversa', 'monstruosa' e produto de uma 'sociabilidade violenta e moralmente degradada', induzindo o modo com que cidade de João Pessoa, "ainda consternada, revoltada e enfurecida" (Junior 2009) passou a viver com o caso. O que gerou pânico moral (Cohen 2002).

As tensões permanentes experienciadas por um social, em constante remodelação, vez ou outra, geram instâncias nas quais indivíduos e grupos provocam situações ou promovem eventos, sentidos pela sociedade mais ampla (cidade, estado, país) como ameaças aos valores sociais. Situações estas estereotipadas pela mídia que, segundo Cohen (2002), ao lado de agentes religiosos, políticos e outros, promovem entrincheiramentos morais (Becker 1976), condenando as situações ou eventos tidos como monstruosos ou moralmente degradados, ao mesmo tempo em que conclamam soluções para o problema.

O cenário do crime foi, nesse sentido, estruturado simbolicamente a partir de um recorte do bairro e de seus moradores como lugar de pessoas perigosas, incivilizadas. Tal exigiria da cidade, entendida como poder público e instituições cidadãs, uma reação imediata de controle social pela ocupação ostensiva do bairro através de um projeto de pacificação do lugar.

O projeto de pacificação abarcaria também a administração do imaginário da tragédia mediante uma política de memória (Ricoeur 
2007) através da construção de uma capela em homenagem às vítimas. Este marco simbólico teria principalmente a função de impedir o esquecimento do evento que desqualificou a reputação moral da cidade e de rememorar permanentemente ao Varjão/Rangel a necessidade de uma vigilância constante do passado a ser superado.

Esta imagem de passado do bairro associada pela mídia à tragédia enquadrou o lugar como sociabilidade moralmente degradada e exemplificada no crime hediondo e banal que destruiu a vida de sete pessoas de uma mesma família e na figura do monstro do Rangel. A partir deste argumento ganha força o projeto de construção de uma capela como monumento à paz e aos valores morais da família paraibana sobre os escombros da casa demolida da família chacinada. A mídia, assim, articulada à prefeitura de João Pessoa, ao governo do estado da Paraíba e à Igreja, assume uma postura de guardiã moral, trazendo para si a missão de mobilizar as atenções da população para uma intervenção moralizadora e saneadora do lugar.

As notícias abaixo registram o papel da mídia local como empreendedor moral e como ator político que articula um projeto de pacificação e memória da tragédia no bairro e na cidade. Nestes textos do noticiário local, abaixo, aparecem os momentos de participação de profissionais da mídia no enquadramento e definição da situação e também no agenciamento de instituições, pessoas e recursos para o desenvolvimento das ideias e da construção do memorial às vítimas da tragédia.

Neste contexto, o próprio radialista mentor da ideia de um monumento à paz mobiliza o sentimento de vergonha desgraça da situação limite ali instaurada, induzindo moradores consternados, revoltados e enfurecidos com a barbárie à demolição ilegal da casa das vítimas. $\mathrm{O}$ próprio também participa do ato, performatizando o papel da mídia como empreendedor moral no âmbito das disputas morais que buscavam enquadrar a tragédia e provocar consequências políticas de controle e moralização do Varjão/Rangel e, por extensão, de toda a cidade.

O radialista Emerson Machado, em seu programa diário de rádio, deu a idéia de que fosse feita uma homenagem póstuma as vitimas da 
'Chacina do Rangel', com a construção de uma capela no local onde sete pessoas da mesma família foram barbaramente assassinadas a golpes de facão, por Carlos José e sua companheira Edileusa. A sugestão dada por Emerson Machado induziu a população ainda consternada, revoltada e enfurecida com a barbárie ocorrida naquela comunidade, a agirem sob a margem da lei. Inclusive, o próprio Emerson, usou uma marreta para ajudar na demolição da casa, conforme mostra a foto tirada pelo Jornalista Clilson Junior (2009).

O sentimento de vergonha desgraça gerado pelo enquadramento moral da situação limite representada pela chacina é compreendido não a partir da dinâmica do crime tomado isoladamente, mas pelo que representou ao esforço conjunto do bairro em se transformar em Rangel, superando a identidade Varjão. Ao nomear a chacina e o seu 'monstro' como do Rangel, todo um esforço coletivo parece ter sido desacreditado.

O descrédito da reputação moral do Rangel gera a situação limite que configura, de um lado, a revolta dos moradores do bairro em relação à chacina e ao seu cenário, pelo que estes representaram ao esforço de superação em prol de um bairro ordeiro e civilizado, o Rangel. A apropriação moral da chacina pelos empreendedores morais da cidade, assim, provoca, na visão dos moradores do Varjão/Rangel, uma nova desdita, invocada pelo conceito scheffniano de vergonha desgraça, e que desorganiza a carreira moral idealizada pelos moradores de um espaço integrado e aceito em João Pessoa.

A experiência de vergonha desgraça traz ao cotidiano uma quebra irreversível dos vínculos possíveis do bairro do Rangel à cidade, como um espaço de inclusão, de gente ordeira e honesta. Ao associar a chacina ao Rangel, a mídia, e a cidade constrangida, associaram, segundo os moradores, o Rangel ao Varjão, o que, no imaginário local, impediria a concretização de um sonho de pertença à cidade por caminhos outros que não os do estigma, da exclusão simbólica e da humilhação: isto é, os de não serem olhados como possíveis marginais, e de não se sentirem excluídos e estigmatizados como Varjão. 
Este complexo de vínculos engolfados (Scheff 1990) e moralmente confusos, provoca o sentimento de revolta dos moradores do bairro contra o crime. Crime este instrumentalizado por cruzados morais para a construção da situação limite jaspersiana e da amplificação da vergonha como instituição para além da vergonha cotidiana, em sua expressão de falência moral sentida individual e coletivamente como vergonha desgraça.

Percebe-se um ressentimento latente, reforçado desde então, por parte dos moradores do Rangel em relação à cidade de João Pessoa. Muito embora a luta dos moradores para a mudança do nome do bairro de Varjão para Rangel - há uma transferência imaginária de uma situação de Varjão para um projeto de Rangel como um bairro digno, honrado, de família e respeitado pela cidade - como uma forma de melhorar a imagem do bairro por parte da cidade tenha sido aceita pela maioria das instituições municipais, se continua a atribuir as mazelas do bairro considerado pelos moradores como Varjão, ao Rangel. Os moradores, assim, se ressentem e se colocam como traídos e abandonados no seu esforço de melhoria e modernização do bairro, o Rangel.

No desenrolar dos fatos seguintes ao crime, à prisão dos criminosos, à tortura do 'Monstro do Rangel', à demolição das casas das famílias envolvidas na chacina, ou seja, quando o poder de ressignificar a tragédia, assim como de administrar as tensões avivadas no bairro do Varjão/Rangel, passou a ser disputado moralmente não só pela mídia local, mas também por outros atores sociais relevantes na cidade, a Igreja Católica se posiciona no sentido de abençoar o projeto de retomada simbólica do local através da limpeza do mal enraizado naquele terreno onde ocorrera o crime. $\mathrm{O}$ arcebispo da Paraíba, neste sentido, recebe, em seu palácio, parentes das vítimas da chacina, assim como personagens destacados da mídia popularesca e humorística da cidade.

Trata-se de uma aproximação simbólica das angústias e sofrimentos do povo, envergonhado e ressentido com a chacina e suas consequencias, por parte de autoridades religiosas e civis. Autoridades estas 
que performatizam atitudes e discursos de carisma e solidariedade em relação às vítimas, sem, contudo, provocar um enfrentamento da ira/ raiva, do ódio e da vergonha desgraça que acometeu a população da cidade. $\mathrm{O}$ trecho de notícia abaixo registra a participação conjunta da mídia e da igreja católica no contexto de enquadramento moral das consequencias da tragédia:

"Na ultima segunda-feira (11) o Arcebispo da Paraíba Dom Aldo Pagotto autorizou a construção de um Santuário como forma de eternizar a memória das vítimas da chacina do Rangel. O líder religioso recebeu na manhã de hoje no Palácio do Bispo familiares das vítimas em companhia do radialista Samuka Duarte da 107 FM e TV Arapuan" (http://manchetepb. blogspot.com.br/2009/07/mesmo-com-delegado-proibindo-populacao.html; acesso em 7/7/15).

$\bigcirc$ projeto de construção da capela, santuário dos inocentes ou monumento à paz, como idealizado pelos empreendedores morais que buscaram enquadrar moral e politicamente o crime, será, no desdobrar-se das disputas e desentendimentos cotidianos entre moradores do bairro, mídia local, igreja católica e poder público municipal, interrompido. A mídia local e a igreja católica foram, neste processo, surpreendidos pela ação da polícia civil, que apontou irregularidades e ilegalidades na condução do projeto da capela, refreando, assim, a capacidade destes atores sociais em perfomatizar discursos de moralização da cidade e do Varjão/Rangel.

"Na ultima segunda-feira (11) o Arcebispo da Paraíba Dom Aldo Pagotto autorizou a construção de um Santuário como forma de eternizar a memória das vítimas da chacina do Rangel.

Até ai tudo bem, a intenção é louvável, no entanto, esqueceram de perguntar a opinião dos sobreviventes, legítimos herdeiros do imóvel em questão, se eles estariam de acordo que o único bem concreto deixado pelos pais, fosse demolido para construir um santuário no local. Segundo o Art. $28 \S 1^{\circ}$ do ECA, a criança ou adolescente deverá ser previamente ouvido e a sua opinião devidamente considerada. Todavia, o Delegado responsável pelo caso, emitiu um ofício aos familiares das vítimas, proibindo a demolição da casa, alegando haver necessidade de ser feita novas perícias no local, para dirimir algumas dúvidas que possam surgir no inquérito policial”. 
A construção induzida de um espaço de memória e reconfiguração simbólica, quase de batismo de uma nova sociabilidade, com base em trabalhos voluntários e doações de materiais de construção e dinheiro, e que orientasse procissões e atividades religiosas para àquele local, estava, na época, em vias de assumir um caráter mágico -religioso. É neste momento que o poder público municipal assume mais fortemente a condução do processo de pacificação do bairro, retirando da mídia local, da igreja católica e dos moradores do bairro a responsabilidade pela limpeza simbólica do bairro.

Uma vez suspensas as iniciativas populares, o poder público da cidade investe em um processo de pacificação em médio prazo da sociabilidade do bairro. Por pacificação se entende aqui um aumento considerável de reforço policial em todo o bairro ${ }^{15}$. Reforço este chegando, em algumas horas de maior movimentação, a bloquear as entradas e saídas do Varjão/Rangel, por si só já confinado nos limites da Mata do Buraquinho, que margeia o território do bairro.

O processo de pacificação do Varjão/Rangel pelo poder público municipal tem provocado, desde 2009, uma reconfiguração significativa do espaço no sentido de situá-lo como recurso estratégico para a mobilização urbana, transformando-o em um corredor para o transporte coletivo ligeiro e como ponte entre diversos bairros de João Pessoa. A este processo juntam-se esforços de ressignificação da área como espaço de uma nova classe média a partir da desorganização dos resquícios de comunidades ainda presentes no Varjão/Rangel.

A paisagem do bairro, tanto geográfica quanto interacional, vem sendo modificada com o calçamento e alinhamento de ruas e com a construção acelerada de pequenos edifícios de até cinco andares. Verifica-se uma substituição dos padrões de moradia e ocupação do território conforme casas e terrenos das comunidades tradicionais vão sendo vendidos e repassados para empreiteiras da cidade.

O sentimento de vergonha desgraça ocasionado pela apropriação moral da 'Chacina do Rangel' pela cidade, passados seis anos desde o evento, não mais caracteriza a sociabilidade local. A vergonha desgra- 
ça, neste sentido, parece estar associada a situações limite, de intensa liminaridade, em que disputas morais se agravam e rituais de limpeza, reordenação e refundação de identidades se confrontam com sentimentos de impotência, confusão e baixa estima (Sennet 2004).

O que se verifica atualmente na sociabilidade do Varjão/Rangel, um bairro ainda ressentido com a cidade, é a generalização de uma visão irônica sobre a tragédia em decorrência de frustrações e quebras de confiança por parte daqueles que se apresentaram como empreendedores morais da situação. Até mesmo alguns familiares de uma das vítimas foram desacreditados e acusados de apropriação da boa-fé dos moradores do bairro, quando ainda sob o impacto da tragédia e em processo de construção de um monumento à paz que jamais se concluiu: trabalho voluntário se perdeu e doações de recursos e materiais foram desviadas para fins pessoais.

A vergonha desgraça e um acentuado ressentimento definiram a sociabilidade do bairro no momento da tragédia, quando se instala uma situação generalizada de pânico e falência moral. Passada esta situação limite, a vergonha desgraça é gradativamente substituída pela vergonha cotidiana e o ressentimento pela ironia.

Esta configuração moral e emocional da sociabilidade do bairro, muito embora não exclua sentimentos de humilhação e estigma, permite a administração de informações sensíveis e desacreditáveis sobre o bairro e seu morador. Desta maneira, a administração cotidiana das tensões, nos mais variados formatos emocionais e morais, se articula como espaço interacional possível para a organização de projetos de vida, individuais e coletivos.

A pressão moral desencadeada pela 'Chacina do Rangel', oportunamente apropriada como cruzada moral, inaugura um amplo processo de reorganização do bairro em função da cidade. Contudo, este evento, ou seja, o sentimento de vergonha desgraça ali gerado, não mais significa uma ameaça de ruptura simbólica com a cidade.

Atualmente, verifica-se que a indiferenciação entre Varjão e Rangel, potencializada pela tragédia, no imaginário da cidade, vem sendo 
superada conforme a chacina se distancia no tempo. O Rangel se estabelece uma vez mais como possibilidade de um projeto coletivo de bairro, com toda a sua carga moral de vergonha cotidiana e de medos corriqueiros, em relação a um Varjão que se quer vencer e tende a permanecer no habitus dos moradores e nas relações entre cidade e bairro.

\section{Notas}

1 Este crime, ainda bastante atual no imaginário da cidade e explorado exaustivamente pela mídia local e também nacional, pôs em relevo a sociabilidade do Varjão/Rangel não somente como violenta e perigosa, mas também como um espaço de interações em processo adiantado de falência moral, ou seja, em que os vínculos sociais, fragilizados e na iminência do rompimento, se configuram como emoções negativas de medos, vergonha desgraça, estigma, desconsideração, desconfiança, ira, raiva, vingança e outras. 2 O conceito de vergonha desgraça, desenvolvido por Scheff (1990), aponta para uma situação de quebra dos vínculos sociais e de intensa desorganização moral e emocional do espaço interacional, gerando um forte desequilíbrio na rede de relações e podendo vir a desatar dinâmicas de ira, medos, ressentimentos, raiva e violência simbólica.

3 A banalidade aqui referida diz respeito não à crueldade do evento em si, mas ao modo corriqueiro de crimes violentos, onde a forma cruel dos assassinatos [torturas, apedrejamentos, usos de marretas, corpos retalhados, e outros] ocorre e é noticiada no cotidiano da imprensa da cidade de João Pessoa, sem, contudo, se transformar em escândalo, espetacularização, argumento e apropriação moral, como o fato da chacina retratada neste artigo.

4 Como a maior parte dos bairros populares da capital, o bairro do Varjão/Rangel foi ocupado por levas frequentes de antigos moradores de cidades interioranas que vieram para a capital em busca de emprego e de uma melhor condição de vida para si e família. Migração que se deu (e ainda ocorre) em rede, onde um parente, amigo, vizinho, conhecido da cidade de origem entrava em contato com outro já morador de João Pessoa e, através dele, vinha para a capital e se instalava na casa desses já moradores e, logo após, em um 'puxado' que construía no terreno do morador ou próximo a ele, que também servia como um elemento que ajudava a esses novos moradores a se inserirem na economia informal e, em poucos casos, na economia formal da cidade. O bairro do Varjão/Rangel, como os demais bairros populares da cidade, cresceu, assim, em um processo contínuo de ocupações realizadas através de redes de parentesco ou de vizinhança e amizade, que se aprofundava no novo local através de laços de gratidão dos novos habitantes pela solidariedade dos já mora- 
dores. O que refundava laços rompidos anteriormente, na vinda desses primeiros moradores, ou criava laços novos, pelo recebimento de novos sujeitos não tão próximos, mas indicados por parentes e amigos que ficaram nos municípios de origem.

5 Trata-se de um cenário classificado moralmente pela cidade como um dos bairros mais violentos e problemáticos do espaço urbano local, de modo que o atributo moral do bairro se coloca para o seu morador como um elemento de embaraço e constrangimentos cotidianos, estigma, humilhação, silêncios e interditos. Este mesmo morador classifica o outro próximo e a si mesmo a partir dos códigos de moralidade da cidade onde o bairro se situa como área popular, recriando a lógica hierarquizante da própria cidade que atribui qualidades morais negativas aos seus moradores, desqualificando-os em relação aos códigos morais vistos como positivos pela cidade.

6 Fala de uma moradora da Rua Oswaldo Lemos, no Varjão/Rangel, João Pessoa - PB. Fonte: (https://www.youtube.com/watch?v=_je10Dx9ocA, VídeosParaíba1, Especial - Chacina do Rangel, enviado em 08 de outubro de 2009).

7 Simmel discute o processo de socialidade construído pela confiança e lealdade como um processo que estabelece uma igualdade desigual entre os membros do grupo, no caso as duas famílias, e comenta que esta forma desigual da igualdade é invisível ou inconsciente às partes relacionais, mas sempre desperta quando cada uma das partes se sente ameaçada pelo outra. Ou seja, em Simmel, a base da confiança é a busca de uma lealdade total, sempre quebrada pela possibilidade da desconfiança que paira como uma ameaça sobre as sólidas relações estabelecidas em um grupo de iguais. A antecipação da traição por sua vez, se estabelece os limites para cada ato de confiabilidade entre os membros do grupo, possibilita, também, a renovação dos laços e um aprimoramento das regras de confiança que une o grupo e seus membros. $\mathrm{O}$ grupo e seus membros se movem, assim, em uma tensão permanente entre a união e a desunião possível, o que estabelece um processo de vergonha social, que povoa e sedimenta a moral grupal, assim como aponta para as possíveis falhas e leva a desavenças e a sentimentos de raiva e endurecimento de ações caso uma das partes se sinta lesada por um acontecimento ou ação provocada pela outra parte.

8 Fonte: Blog do Clilson, 'Chacina do Rangel', postado em 18 de Julho de 2009. (https://www.youtube.com/watch?v=TFi2tl7G4f8).

9 'Chacina no Rangel: 4 pessoas de uma mesma família são executadas a golpes de facão'. (http://www.clikPB.com.br, de 09 de julho de 2009).

10 In: O-Be-a-Bá-do-Sertão. (http://www.obeabadosertao.com.br/v3/chacina_sete_ pessoas_da_mesma_familia_sao_assassinadas_2177.html).

11 Vídeo anônimo intitulado 'Chacina do Rangel: Morre praga da sociedade'. Postado no You Tube em 16.07.2009. (https://www.youtube.com/watch?v=bQP6T4UuhIk).

12 'Casa da família vítima da Chacina é derrubada'. PB Agora - A Paraíba o tempo todo - (www. pbagora.com.br).

13 (http://www.wscom.com.br/noticia/paraiba/capela+das+vitimas+não+passa+de+entulho+-89958).

14 Fonte: Blog O-be-a-Bá do Sertão - Paraíba. (http://www.obeabadosertao.com.br/ 
v3/ chacina_sete_pessoas_da_mesma_familia_sao_assassinadas_2177.html).

15 As patrulhas policiais são vistas ainda a rodar toda a noite pelas vias principais do bairro, bem como pelas áreas consideradas como de maior risco à segurança dos moradores e da cidade. $\mathrm{O}$ que tem causado impactos considerados positivos por moradores que se dizem 'mais protegidos', mas, ao mesmo tempo em que revelam preocupação com a própria segurança pessoal nos casos em que são abordados e confundidos com possíveis 'marginais' pelos efetivos policiais.

\section{Referências}

BARBOSA, Raoni Borges. 2016. Emoções, Lugares e Memórias: Um estudo sobre as apropriações morais da 'Chacina do Rangel'. Projeto de pesquisa qualificado em março de 2016. Recife: PPGA/UFPE.

BECKER, Howard S. 1976. Uma teoria de ação coletiva. Rio de Janeiro: Zahar. . 2008. Outsiders: estudos de sociologia do desvio. Rio de Janeiro: Jorge Zahar. .2009. Falando da sociedade: ensaios sobre as diferentes maneiras de representar o social. Rio de Janeiro: Jorge Zahar.

BERGER, Peter. 2001. Perspectivas sociológicas: uma visão humanistica. Petrópolis: Vozes. . 2015. "Sobre a obsolescência do conceito de honra, [seguido de] Duas notas de rodapé sobre a obsolescência da honra". RBSE - Revista Brasileira de Sociologia da Emoção, 14(41):7-20.

CARDOSO DE OLIVEIRA, Luís R. 2011. Direito legal e insulto moral: Dilemas da Cidadania no Brasil, Quebec e EUA. Rio de Janeiro: Garamond.

COHEN, Stanley. 2002. Folk devils and moral panics. London: Routledge.

ELIAS, Norbert. 1994. A sociedade dos indivíduos, Rio de Janeiro: Jorge Zahar.

GARLAND, D. 2008. "On the concept of moral panic". Crime, Media, Culture, 4(1):9-30.

GOFFMAN, Erving. 1988. Estigma: Notas sobre a manipulação da identidade deteriorada. Rio de Janeiro: Editora Guanabara. Vozes.

GOODE, E. \& BEN-YEHUDA, N. 1994. Moral Panics: The Social Construction of Deviance. Oxford: Blackwell Publishers.

JASPERS, Karl. 1974. Die Schuldfrage: Von der politischen Haftung Deutschlands. München: Pieper.

JUNIOR, Clilson. Incentivados por Emerson Machado população ignora ordem de não demolir casa da chacina do Rangel. In Blog Soltando o verbo. (http://soltandooverbo.com.br/2009/07/19/incentivados-por-emersonmachado-populacao-ignora-ordem-de-nao-demolir-casa-da-chacina-do-rangel/; acesso em 7/7/2015). 
KOURY, Mauro G. P. 2000. Medos corriqueiros: a construção social da semelhança e da dessemelhança entre os habitantes das cidades brasileiras na contemporaneidade. Projeto de Pesquisa, GREM/DCS/UFPB.

. 2002. "Medos Corriqueiros, vida cotidiana e sociabilidade". Política $\mathbb{E}$ Trabalho - Revista de Ciências Sociais, 18(*):09-21.

. 2003. "O local enquanto elemento intrínseco da pertença". In LEITÃO,

Cláudia (ed.): Gestão Cultural, pp. 75-88. Fortaleza: Banco do Nordeste. . 2005. Medos Corriqueiros e Sociabilidade. João Pessoa: Edições GREM/ Editora Universitária UFPB.

. 2005a. "Viver a cidade: um estudo sobre pertença e medos". RBSE Revista Brasileira de Sociologia da Emoção, 4(11):148-156.

. 2008. De que João Pessoa tem Medo? Uma abordagem em Antropologia das emoções. João Pessoa: EdUFPB.

. 2009. Emoções, Sociedade e Cultura: A categoria de análise Emoções como objeto de investigação na sociologia. Curitiba: Ed. CRV.

2010. "Estilos de vida e individualidade". Horizontes Antropológicos, $16(33): 41-53$.

2010a. "Identidade e pertença: disposições morais e disciplinares em um grupo de jovens". Etnográfica, 12(1):27-58.

. 2011. "Medos Corriqueiros urbanos e mídia: o imaginário sobre juventude e violência no Brasil atual". Revista Sociedade e Estado, 26(3):471-485.

. 2012. Análise de um bairro considerado violento na cidade de João

Pessoa, Paraíba: Solidariedade e conflito nos processos de interação cotidiana sob intensa pessoalidade. (Projeto MCTI/CNPq, N 14/2012). João Pessoa: GREM.

KOURY, Mauro G. P. et al. 2013. "Como se articulam vergonha e quebra de confiança na justificação da ação moral?". Dilemas: Revista de Estudos de Conflito e Controle Social, 6(2):251-268.

PARK, Robert et al. 1925. The city. Chicago: University of Chicago Press.

REZENDE, Cláudia B. \& COELHO, Maria C. 2010. Antropologia das Emoções. Rio de Janeiro: Editora FGV.

RICOEUR, Paul. 2007. A memória, a história, o esquecimento. Campinas: EdUNICAMP.

SCHEFF, Thomas J. 1990. Microsociology: discourse, emotion, and social structure. Chicago: University Of Chicago Press.

SENNET, Richard. 2004. Desrespeito: a formação do caráter em um mundo desigual. Rio de Janeiro: Record.

SIMMEL, Georg. 2003. "Fidelidade: Uma tentativa de análise sócio-psicológica". RBSE - Revista Brasileira de Sociologia da Emoção, 2(6):513-519. . 2010. "Gratidão: Um experimento sociológico". RBSE - Revista Brasileira de Sociologia da Emoção, 9(26):785-804. 
TURNER, Victor. 1974. O Processo Ritual. Petrópolis: Vozes.

WERNECK, Alexandre. 2009. O invento de Adão: O papel do ato de dar uma desculpa na manutenção das relações sociais. Tese de Doutorado. Rio de Janeiro: IFCS/ UFRJ.

2011. "O egoísmo como competência: um estudo de desculpas dadas nas relações de casal como forma de coordenação entre bem de si e moralidade". Revista de Antropologia, 54(1):133-190.

YOUNG, J. 1971. "The Role of the Police as Amplifiers of Deviancy". In COHEN, Stanley (ed.): Images of Deviance, pp. 27-61, Harmondsworth: Penguin.

\begin{abstract}
This article discusses the moral dispute around a panic regime established by the media under the impact of a massacre spectacularized as 'Chacina do Rangel' in the daily life of residents of the popular neighborhood Varjão / Rangel, in the city of João Pessoa, Paraíba, Brazil. The popular neighborhood Varjão / Rangel was highlighted in the city of João Pessoa for the cruelty and banality of the slaughter, which mobilized a series of processes of moral appropriation and social control by the public power, the media and the church, especially the Catholic Church. The discussion developed in this article emphasizes the moral dispute that occurred shortly after the 'Rangel's Slaughter' around a project to create a sanctuary in memory of the victims of the slaughter at the place where the tragedy happened. The article makes an ethnography of the negotiations, the tensions, the disagreements and the impasses surrounding the possibility of the construction of the sanctuary, which occur simultaneously to the process initiated by the public power of pacification of the neighborhood Varjão / Rangel, as a form of social control of a place stigmatized as violent and dangerous.
\end{abstract}

Keywords: Varjão/ Rangel; Slaughter; 'Chacina do Rangel'; Moral panic; Moral dispute;Sanctuary.

Recebido em maio de 2017. Aprovado em junho de 2018. 